\title{
Pattern of Admission and Outcome of Neonates in a NICU of Tribal Region Bastar, India
}

\author{
${\text { Bhagat Baghel }{ }^{1 *} \text {, Anurup Sahu }{ }^{1}, \text { K. Vishwanadham }}^{2}$ \\ ${ }^{1}$ Associate Professor, 2Professor, \\ Department of Paediatrics, Late BRKM Govt. Medical College, Jagdalpur, Bastar, Chattisgarh, India.
}

\begin{abstract}
Objective: To know the pattern of admission and outcome of neonates in NICU.

Material \& Methods: The study is a retrospective review of cases managed in the neonatal unit of the Late BRKM Govt. Medical College cum Maharani Hospital Jagdalpur, Chhattisgarh, India. Data extracted included: The age of neonate on admission, sex, weight on admission or at birth, inside and outside delivered babies, final diagnosis, and outcomes and cause of death.

Results: During the period of study, a total of 1502 neonates were admitted in the NICU. Of the 1502, $67.77 \%$ were inborn and $32.24 \%$ were outside delivered babies. The weight wise distribution of all the admissions were ELBW 3.4\%), VLBW $18.06 \%$, LBW $42.74 \%$ and remaining babies had normal birth weight. Half of the babies admitted in our NICU were preterm $(51.99 \%)$, followed by hypoxic ischemic encephalopathy $23.30 \%$, neonatal septicemia $12.98 \%$, neonatal jaundice $6.12 \%$. Out of 1502 admitted neonates in the NICU, $55.59 \%$ babies were discharged successfully, $15.54 \%$ were given discharged on request and $21.50 \%$ died. In our study commonest associated cause of neonatal mortality was prematurity $54.98 \%$, while other causes of death were HIE $32.19 \%$, neonatal sepsis $9.90 \%$. The mortality percent in outside delivered babies was just double $32.8 \%$ then inside delivered babies $16.1 \%$.
\end{abstract}

\section{INTRODUCTION}

Newborn infants are unique in their physiology and health problems that they experience. Neonatal period is characterized by transition to extra uterine life ad rapid growth and development. Newborn health is the key to child health and survival. About 0.76 million neonates die every year in India, the highest for any country in the world. The neonatal mortality rate (NMR) of the country did decline from 52 per 1000 live births in 1990 to 29 per 1000 live births in 2012 (SRS 2012) but the rate of decline has been slow, and lags behind that of infant and under-five child mortality rates. The slower decline has led to increasing contribution of neonatal mortality to infant mortality. With the current infant and under-five child mortality rates of 42 and 52 per 1000 live births respectively (SRS 2012), about $70 \%$ of infant deaths and more than half of under-five child deaths occur in the neonatal period, the first 4 weeks of life. The three major causes
Conclusion: In our study, prematurity, HIE and sepsis are the common causes for admission and mortality in newborn babies of our NICU. Most of the morbidities and subsequent mortalities can be prevented by improving the basic nursing care and effective implementation of preventive services like maternal care, $I \mathrm{MNCl}$, timely interventions and timely referral to tertiary care centers.

Key Words: NICU, Prematurity, LBW, Neonatal admission, Neonatal death.

\section{${ }^{*}$ Correspondence to:}

Dr. Bhagat Baghel,

Associate Professor,

Department of Paediatrics,

Late BRKM Govt. Medical College,

Jagdalpur, Bastar, Chattisgarh, India.

Article History:

Received: 28-10-2016, Revised: 23-11-2016, Accepted: 30-11-2016

\begin{tabular}{|l|c|}
\hline \multicolumn{2}{|c|}{ Access this article online } \\
\hline $\begin{array}{l}\text { Website: } \\
\text { www.ijmrp.com }\end{array}$ & Quick Response code \\
\hline DOI: & \\
10.21276/ijmrp.2016.2.6.029 & \\
\hline
\end{tabular}

of neonatal deaths are preterm birth complications, infections, and intrapartum related complications; together, they contribute to nearly $90 \%$ of total neonatal deaths. While almost all of intrapartum-related deaths and majority of prematurity-related deaths occur in the first week of life, more than half of infection related deaths occur after the first week of life. This has implications for the home/community-based postnatal care of neonates ${ }^{1}$.

\section{MATERIALS AND METHODS}

The study was a review of cases managed in the neonatal unit of the Late BRKM Govt. Medical College cum Maharani Hospital Jagdalpur, Chhattisgarh, India. Babies admitted in our unit are from within the hospital and also receives referral from various govt. and private hospitals of entire Bastar division and some 
areas of Orissa state. Facilities available in our NICU include 20 radiant warmers, 8 Phototherapy units, 4 syringe pumps and 3 multipara monitors. In the postnatal ward, babies who were ill but do not require intensive or special care are admitted with their mothers and managed there only.

It was a retrospective descriptive study of records of neonates admitted into the neonatal unit between 1 August 2014 and 30 July 2015 over a period of one year. Data on all neonates admitted into the neonatal unit were collected from the admission, discharge, and death registers. Data extracted included: The age of neonate on admission, sex, weight on admission or at birth, inside and outside delivered babies, main final diagnosis, and outcomes (discharge, death or left against medical advice) and cause of death. Approval for the study was obtained from the hospital and ethical committee.

Table 1: Sex wise distribution of admission

\begin{tabular}{lcc}
\hline Sex & Admission & Percentage \\
\hline Male & 787 & 52.39 \\
Female & 715 & 47.71 \\
Total & 1502 & \\
\hline
\end{tabular}

Table 2: Admission ratio of Inside and outside delivered babies

\begin{tabular}{lcc}
\hline & Admission & Percentage \\
\hline Inside delivered & 1018 & $67.77 \%$ \\
Outside delivered & 484 & $32.24 \%$ \\
\hline
\end{tabular}

Table 3: Weight wise distribution of admission

\begin{tabular}{lcc}
\hline Weight categary & Admission (1502) & Percentage \\
\hline ELBW & 52 & $3.4 \%$ \\
VLBW & 271 & $18.04 \%$ \\
LBW & 642 & $42.74 \%$ \\
$>\mathbf{2 . 5}$ kg & 537 & $35.75 \%$ \\
\hline
\end{tabular}

Table 4: Term wise distribution of admission

\begin{tabular}{lcc}
\hline & Admission (1502) & Percentage \\
\hline Preterm & 781 & $51.99 \%$ \\
Fullterm & 721 & $48.09 \%$ \\
\hline
\end{tabular}

Table 5: Cause wise admission in NICU

\begin{tabular}{lcc}
\hline Cause & Admission & Percentage \\
\hline Preterm & 781 & $51.99 \%$ \\
HIE & 350 & $23.30 \%$ \\
Neonatal sepsis & 195 & $12.98 \%$ \\
Neonatal jaundice & 92 & $6.125 \%$ \\
Neonatal seizure & 45 & $2.99 \%$ \\
MAS Cong. & 19 & $1.34 \%$ \\
Other (CHD, Cotion) & & $1.26 \%$ \\
Malformation, aspiration & \\
\hline
\end{tabular}

Table 6: Various outcomes of NICU

\begin{tabular}{lcc}
\hline Outcome & Admission (1502) & Percent \\
\hline Discharge & 835 & $55.59 \%$ \\
DOR & 233 & $15.54 \%$ \\
Death & 323 & $21.50 \%$ \\
LAMA & 68 & $4.52 \%$ \\
Abscond & 30 & $1.99 \%$ \\
Refer & 13 & $0.86 \%$ \\
\hline
\end{tabular}

Table 7: Weight wise distribution of admission and death

\begin{tabular}{lccc}
\hline & Admission & Death & Percentage \\
\hline ELBW & 52 & 34 & $65.38 \%$ \\
VLBW & 271 & 103 & $38.00 \%$ \\
LBW & 642 & 112 & $17.44 \%$ \\
$>\mathbf{2 . 5}$ kg & 537 & 74 & $13.78 \%$ \\
& 1502 & 323 & \\
\hline
\end{tabular}

Table 8: Distribution of cause of death

\begin{tabular}{lcc}
\hline & Death & Percentage \\
\hline Preterm & 176 & $54.48 \%$ \\
HIE & 104 & $32.19 \%$ \\
Neonatal sepsis & 32 & $9.90 \%$ \\
Congenital anomalies & 5 & $1.54 \%$ \\
MAS+ HIE & 3 & $0.92 \%$ \\
Neonatal jaundice & 2 & $0.61 \%$ \\
Other & 1 & $0.31 \%$ \\
\hline
\end{tabular}

Table 9: Death ratio among the inside and outside delivered babies

\begin{tabular}{lcc}
\hline & Death (323) & Percentage \\
\hline Inside delivered & 164 & $54.12 \%$ \\
Outside delivered & 159 & $52.47 \%$ \\
\hline
\end{tabular}

Table 10: Percentage of death in inside and outside delivered babies

\begin{tabular}{lccc}
\hline & Admission & Death & Percent \\
\hline Inside delivered & 1018 & 164 & $16.1 \%$ \\
Outside delivered & 484 & 159 & $32.8 \%$ \\
\hline
\end{tabular}

\section{RESULTS}

During the period of study, there were a total of 1502 neonates admitted to the NICU. Among them $52.3 \%$ were male and $47.7 \%$ female. Of the 1502, $67.7 \%$ were inborn and $32.3 \%$ were outside delivered babies. the weight wise distribution of all the admissions were ELBW $3.4 \% \quad(n=52)$, VLBW $18.06 \% \quad(n=271)$, LBW $42.74 \%(n=642)$ and remaining babies had normal birth weight. Half of the babies admitted in our NICU were preterm (51.99\%), followed by hypoxic ischemic encephalopathy $23.30 \%$, neonatal septicemia $12.98 \%$, neonatal jaundice $6.12 \%$, neonatal seizure 
2.99\%, MAS $1.34 \%$ and others(CHD, congenital anomalies \& aspiration ) $1.26 \%$. Antibiotics and oxygen were the common interventions used for the management, while anticonvulsive therapy was required in 210 patients; phototherapy was used only for 92 babies. Most of the time multiple therapies were used to manage life threatening and morbid conditions.

Of the 1502 neonates admitted in our NICU $55.59 \%$ babies were discharged successfully, $15.54 \%$ were discharged on request and $323(21.50 \%)$ were died. When we see the weight wise correlation of admission and death it was $65.38 \%$ in ELBW, $38 \%$ in VLBW, $17.44 \%$ in LBW and $13.78 \%$ in normal weight babies. In our study commonest associated cause of neonatal mortality was prematurity $54.98 \%$, while other causes of death were HIE $32.19 \%$, neonatal sepsis $9.90 \%$,congenital anomalies $1.54 \%$, MAS + HIE $0.92 \%$ neonatal jaundice $0.61 \%$ and others are responsible for $0.31 \%$ of neonatal deaths. The mortality percent in outside delivered babies was just double $32.8 \%$ then inborn delivered babies $16.1 \%$.

\section{DISCUSSION}

Our study shows that total 1502 newborn babies were admitted in Maharani Hospital Jagdalpur from 1st of August 2014 to 30th July 2015 over a period of one year. Among them $52.3 \%$ male and $47.7 \%$ were female with a male to female ratio of $1.1: 1$. The male predominance in this study is consistent with other studies ${ }^{2}$. This indicates that male neonates are more vulnerable during the neonatal period, a finding in agreement with the well described biological survival of girls in the neonatal period. In our study $67 \%$ were inborn and rest $32 \%$ were outborn babies, who were referred from different private hospitals in the city and Peripheral government hospitals of Bastar, Bijapur, Sukma and Kondagoan districts. Similar findings are reported from study conducted by Patil Ravindra B, K. Raghavendraswamy ${ }^{3}$.

Percentage of ELBW was $3.4 \%$, VLBW $18.06 \%$, LBW $42.74 \%$ and remaining babies had normal birth weight. Findings are very similar from the study conducted by Veena Prasad and Nutan singh 4 .

About half $(51.9 \%)$ of the babies admitted in our hospital were preterm and it was the leading cause of admission in our NICU. This data is similar to only one study conducted by Ike Elizabeth $U$ and Modupe O. Oyetunde ${ }^{5}$ at Ibadan Nigeria (54\%) and rest of the studies the contribution of preterm admission is comparatively less like MS HOQUE, S ALAM $(28 \%)^{6}$, Raghvendra Narayan $(13 \%)^{2}$, Veena Prasad and Nutan singh ${ }^{4}(20 \%)$. The probable explanation for the high contribution of preterm admission is early marriage and poor nutritional status of the mother.

In our study birth asphyxia was the second most common cause of NICU admission accounting for $23.3 \%$. This is similar to the study conducted by Bose O. Toma, Olukemi O(18\%) et al ${ }^{7}$ and lke Elizabeth U, Modupe O.Oyetunde $5(19 \%)$ and Shah GS, Yadav S et $\mathrm{al}^{9}(20.2 \%)$. There are some studies having high and some are low incidence of birth asphyxia when it compare with our observation. MS HOQUE, S ALAM et $a^{6}{ }^{6}(37.7 \%)$ and Jan AZ, Ahmad S, Zahid SB (9.1\%).

In our study Neonatal sepsis contributes $12.9 \%$ of total admission. This is about the same experience in Uttarakhand ${ }^{4}$ where neonatal sepsis accounting for $10 \%$ of total admission. Neonatal jaundice was responsible for $6.12 \%$ of total admission while the reports of other studies are $36 \%$ in Peshawar Pakistan by Jan AZ, Ahmad
$\mathrm{S}^{8}, 11 \%$ in Nigeria by Bose $\mathrm{O}$. Toma, Olukemi $\mathrm{O}$ et $\mathrm{al}^{7}$. Contribution of admission by neonatal seizure and MAS is $2.99 \%$ and $1.34 \%$ respectively. Findings were similar with the study done at Sultan Pakistan ${ }^{10}$.

Of the 1502 neonates admitted in our NICU $55.59 \%$ babies were discharged successfully, $15.54 \%$ were discharged on request and $21.50 \%$ were died. Mortality rate is lower than the studies conducted at Pakistan ${ }^{11}$ and bangladesh ${ }^{6}$ but it is slightly higher when we compare the results of studies conducted in other parts of India ${ }^{3,4}$. Weight wise correlation of admission and death it was $65.38 \%$ in ELBW, $38 \%$ in VLBW, $17.44 \%$ in LBW and $13.78 \%$ in normal weight babies, weight wise mortality is good in comparison to studies conducted in Bangladesh and some parts of India6,3,4

In our study commonest associated cause of neonatal mortality was prematurity $54.98 \%$, while other causes of death were HIE $32.19 \%$, neonatal sepsis $9.90 \%$,congenital anomalies $1.54 \%$, MAS + HIE $0.92 \%$ and neonatal jaundice was responsible for $0.61 \%$ of neonatal deaths. Prematurity was the leading cause of neonatal deaths in the study conducted in other developing countries including India2,3,4,7,10. In our study HIE is accounting for $32.19 \%$ of neonatal death which is slightly higher than the studies conducted in Shivamogga, Karnatka $(8.5 \%)$ and Haldwani Uttarkhand (13.8\%), India 3 ,4.

The mortality percent in outside delivered babies is more than the inside delivered babies which is similar to the study conducted at Shivamogga, Karnataka, India ${ }^{3}$.

\section{CONCLUSION}

According to our study, prematurity, HIE and sepsis are the common causes for admission and mortality in newborn babies of our NICU. Most of the morbidities and subsequently the mortalities can be prevented by improving and effective implementation of important preventive services like maternal care and IMNCI, timely interventions and timely referral to tertiary care centres for delivery of high risk pregnancies and care of neonates in high risk situation. We strongly recommend to increase in manpower to decease in neonatal mortality rate by providing better nursing care in the tribal region like Bastar.

\section{ACKNOWLEDGEMENTS}

The authors are very much thankful for the cooperation of Prof. Dr.K. Vishvanadham and all the staff of NICU.

\section{ETHICAL CONSIDERATIONS}

Approval was taken from Institutional Ethics Committee.

\section{REFERENCES}

1. State of India's Newborn (SOIN) report 2014, released by Ministry of health and family welfare, Government of India 2014. (http://www.newbornwhocc.org/SOIN_PRINTED\%2014-9-

2014.pdf)

2. Raghvendra Narayan. A study of the pattern of admissions and outcome in a neonatal intensive care unit at high altitude; Sri Lanka J Child Health 2012:41(2):79-81.

3. Patil Ravindra B, K. Raghavendraswamy et al. Clinical Profile and Outcome of Babies Admitted to Neonatal Intensive Care Unit Mc Gann Teaching Hospital Shivamogga, Karnataka: A Longitudinal Study. Scholars J Applied Medical Sciences 2014; 2(6G):3357-3360. 
4. Veena prasad and Nutan singh. Causes of morbidity and mortality admitted in Government Medical college Haldwani in Kumoun Region Uttarakhand India. JPBMS (Journal of Pharmaceuticals and Biomedical Scinces) 2011,9(23).

5. Ike Elizabeth U, Modupe O. Oyetunde. Pattern of Diseases and Care Outcomes of Neonates Admitted in Special Care Baby Unit of University College Hospital, Ibadan, Nigeria From 2007 To 2011, IOSR J Nursing Health Science 2015;4(3):62-71.

6. MS Hoque, S Alam et al. Pattern of Neonatal Admissions and Outcome in an Intensive Care Unit of a Tertiary Care Paediatric Hospital in Bangladesh - A One-Year Analysis. Journal of Bangladesh College of Physicians and Surgeons 2013;31(3).

7. Bose O. Toma, Olukemi $O$ et al. Pattern of neonatal admissions and outcome in a tertiary institution in north central Nigeria. Journal of Medicine in the Tropics 2013:15:2:121- 125.

8. Jan AZ, Ahmad S, Zahid SB. Clinical audit of admission pattern and its outcome in a Neonatal ICU. Gomal J Med Sci 2013;11:316.

9. Shah GS, Yadav $S$ et al. Clinical Profile and Outcome of Neonates Admitted to Neonatal Intensive Care Unit (NICU) at a Tertiary Care Centre in Eastern Nepal. Journal of Nepal Pediatric Society 2013;33(3):177-181.
10. Syed R. Ali, Shakeel Ahmed et al. Disease Patterns and Outcomes of Neonatal Admissions at a Secondary Care Hospital in Pakistan Sultan Qaboos Univ Med J 2013; 13(3):424-428.

11. Parkash J, Das N. Pattern of admissions to neonatal unit. J Coll Physicians Surg Pakistan 2005;15(6): 341-4.

\section{Source of Support: Nil.}

\section{Conflict of Interest: None Declared.}

Copyright: (c) the author(s) and publisher. IJMRP is an official publication of Ibn Sina Academy of Medieval Medicine \& Sciences, registered in 2001 under Indian Trusts Act, 1882.

This is an open access article distributed under the terms of the Creative Commons Attribution Non-commercial License, which permits unrestricted non-commercial use, distribution, and reproduction in any medium, provided the original work is properly cited.

Cite this article as: Bhagat Baghel, Anurup Sahu, K. Vishwanadham. Pattern of Admission and Outcome of Neonates in a NICU of Tribal Region Bastar, India. Int J Med Res Prof. 2016; 2(6):147-50. DOI:10.21276/ijmrp.2016.2.6.029 